\title{
Coronary stenting: current and future trends
}

\author{
E J Perrins
}

There can be few technical developments that have changed the face of interventional cardiology so much and so rapidly as the practice of placement of intracoronary stents. It is 10 years since the first stents were implanted in the coronary arteries of humans; since then, stenting has introduced challenges to every part of the health care system in the United Kingdom.

First, the placement of intracoronary stents is undoubtedly associated with a reduced rate of restenosis, both angiographic and clinical. Debate exists as to the magnitude of this effect and its possible relation to the diameter of the coronary artery stented, the length of lesion attempted, the morphology of the lesion, the clinical situation in which it is placed, and the design of the stent itself. However, these questions are not fundamental enough to deter the interventionalist from using the device widely.

Second, and probably even more important in terms of the overall impact of stenting, the availability of a wide range of stents, both in design and physical dimensions, has enabled interventionalists to tackle a broad range of lesions within the coronary circulation. Cardiologists who have become conversant with stenting now regularly perform, as simple interventional procedures, cases that they would not have considered attempting four or five years ago. There is also strong evidence that stenting following reopening of chronic occlusions improves long term patency. Although multivessel angioplasty (PTCA) has long been advocated and practised by a few exponents, stenting has enabled this to become widespread and effective. Although $80 \%$ of PTCA in the UK is still for single vessel disease this percentage is decreasing. Stenting has also greatly reduced the risk for patients who are inoperable by conventional bypass surgery, so that advanced intervention and bypass surgery are complementary techniques.

Third, stenting introduces an additional financial burden, which, in the UK at least, is proving difficult to cope with. The financial burden is exacerbated by the overall increase in interventional procedures stimulated by stent practice. There has been a huge growth over the past five years in the number of procedures performed annually in the UK. It is interesting to note that in the recent report of the Clinical Standards Advisory Group (CSAG) working group, ${ }^{1}$ reforms in the health service would not seem to have had any real impact in the rate of growth of either PTCA or cardiac surgery. However, it has to be remembered that they have grown on average $10 \%$ per year, which is a more accelerated development than many other specialities within the health service that on average have grown only $2-3 \%$ per year.
Despite this huge growth (approximately 20000 procedures in 1996) there has been no real change in the numbers of cardiologists in the regional centres who perform probably the majority, but by no means all, of coronary interventional procedures in the UK. It is clearly a tribute to the profession that it has been able to absorb what is very large new workload, both in terms of time, and of course training and expertise. However, there is a finite limit to the amount of work that the existing practitioners can do, and so the growth of stenting and intervention is going to stress the training system and resources.

The proliferation of stent devices, not to mention the many other interventional technologies, is also stressing the training and competence of the interventional cardiologist and trainees. The recent British Cardiovascular Interventional Society (BCIS) guidelines relating to training and competence have been controversial. ${ }^{2}$ Although there is no doubt that many procedures, including PTCA, can be performed by expert operators running at relatively low total numbers of procedures, that is true only if those operators are performing a narrow range of operations in terms of either patient selection or technical breadth. In a rapidly evolving and developing speciality such as coronary stenting it is simply not possible to be conversant with the various techniques available without performing quite large numbers of procedures each year.

It is for these reasons that BCIS needs to have a very high profile, not only among its members (which includes nearly all interventionalists in the UK) but also with the various professional bodies, particularly the British Cardiac Society, the Royal Colleges and the Department of Health, to try to ensure that appropriate and sensible developments of service occur. Inequality and inequity have been widespread phenomena in the UK health care system, and this has been carefully and systematically documented by the recent CSAG report. This is borne out by recent BCIS audit of interventional procedures in the UK, showing that although the average rate of stent implantation in the country as a whole is approximately $30 \%$, there is a range of $3-75 \%$ (BCIS audit returns 1996; unpublished data). The magnitude of this variation is simply too large and there is going to have to be a concerted effort both on the part of interventionalists, and purchasers and provider managers to resolve some of these issues.

Despite these reservations there is no doubt that coronary stenting is a success story, and I think it is remarkable the extent to which it has already gained a foothold given the difficulties and constraints in the UK. There will always be an urgent need for rigorously carried out clinical trials and hopefully the current trials 
comparing PTCA and stenting with bypass surgery will ultimately prove helpful in clinical decision making. However, one should not forget that, particularly when considering the difficult issue of whether to select a patient for intervention or surgery, surgery itself is going to go through a rapid evolution in the coming years in relation to more minimally invasive techniques. By the time we finally get a good answer as to whether PTCA with stenting is completely equivalent to coronary bypass grafting, the whole stage may have moved in that arena as well.

It is clear that interventional cardiology is going to grow at at least the current rate for some years to come. This is not withstanding the possible explosion that may occur in this specialty if direct intervention for myocardial infarction starts to become established in the UK in the way that it is being established in Europe and North America.

BCIS will continue its commitment to rigorous training and audit of intervention practice in the UK, and there is no doubt that for a while at least the stent will reign supreme within the coronary artery.

1 Black N, Langhan S, Coshall C, Parker J. Impact of the 1991 NHS reforms on the availability and use of coronary revascularisation in the UK (1987-1995). Heart 1996;76(suppl 4):1-32.

2 British Cardiac Society (BCS) and British Cardiovascular Intervention Society (BCIS) working group on interventional cardiology. Planning for coronary angioplasty: guidelines for training and continuing competence. Heart guidelines for trainin

\section{Lesions I don't stent}

Clive A Layton

Ten years have passed since the concept of stenting coronary arteries became a practical reality. ${ }^{1}$ During that time the technique has evolved with improvements in technology, stent design, the design of delivery systems, selection of suitable lesions and technique. Lastly there has been a change in the perceived need for anticoagulation. ${ }^{2}$

Contraindications have evolved in parallel with these developments. Whereas stenting for any indication other than an angioplasty disaster was exceptional, results of observational studies $^{3}$ and randomised trials ${ }^{4}$ have led to a reappraisal. Indications have broadened so that many units use stents in $50 \%$ or more of angioplasties. Conservative units with stenting rates of $20 \%$ or less find it increasingly difficult to justify their reluctance to stent.

Factors previously considered as contraindications to stenting, such as large branches, long lesions, lesions on sharp bends, and increased risk of anticoagulants are no longer considered to be so significant. Even the left main stem is no longer immune from stenting as a bailout procedure, even when not protected by one or more bypass grafts. Wire stents can be used on sharp bends or to cover large side-branches and in the left main stem. Longer stents allow a range of lengths to be covered. Greater awareness of the role of antiplatelet agents, including IIb/IIIa receptor inhibitors, has reduced the risk of subacute stent occlusion and haemorrhage. Lesions in vessels where the approach to the site of the stenosis is extremely tortuous continue to pre- sent a challenging problem but improvements in delivery system design and the use of stiffer wires to straighten the target vessel temporarily make these lesions more amenable, and the contraindication is now relative rather than absolute.

I define only two categories as absolutely unsuitable for stenting. First, lesions that cannot be predilated, identified by persistent indentation during predilatation at whatever pressure is applied. These lesions, if stented, continue to show indentation of the stent, which can be confirmed using intracoronary ultrasound, and the risk of subacute occlusion is high. It is important to distinguish these lesions from those in which the balloon indentation disappears during predilatation but angiography immediately afterwards shows the stenosis to remain because of recoil. These lesions will respond well to stenting. Second, lesions in vessels smaller than $2.5 \mathrm{~mm}$ diameter are not stented because of the incidence of thrombosis and restenosis.

1 Sigwart U, Puel J, Mirkovitch V, Joffre F, Kappenberger L. Intravascular stents to prevent occlusion and restenosis after transluminal angioplasty. $N$ Engl $f$ Med 1987;316: 701-6.

2 Schomig A, Neumann FJ, Kastrati A, Schuhlen H, Blasini $\mathrm{R}$, Hadamitzky $\mathrm{M}$, et al. A randomized comparison of antiplatelet and anticoagulant therapy after the placement of coronary artery stents. $N$ Engl $\mathcal{F}$ Med 1996;334: 1084-9.

3 Vaishnav S, Aziz S, Layton C. Clinical experience with the Wiktor stent in native coronary arteries and coronary bypass grafts. Br Heart $\mathcal{f}$ 1994;72:288-93.

4 Serruys PW, de Jaegere P, Kiemeneij F, Macaya C, Rutsch W, Heyndrickx G, et al. A comparison of balloonexpandable-stent implantation with balloon angioplasty in patients with coronary artery disease. $N \mathrm{Engl} \mathscr{f} \mathrm{Med}$ 1994;331:489-95. 